\title{
BMJ Open What do you think overdiagnosis means? A qualitative analysis of responses from a national community survey of Australians
}

\author{
Ray Moynihan, ${ }^{1}$ Brooke Nickel, ${ }^{2}$ Jolyn Hersch, ${ }^{2}$ Jenny Doust, ${ }^{1}$ Alexandra Barratt, ${ }^{2}$ \\ Elaine Beller, ${ }^{1}$ Kirsten McCaffery ${ }^{2}$
}

To cite: Moynihan $\mathrm{R}$, Nickel B, Hersch J, et al. What do you think overdiagnosis means? A qualitative analysis of responses from a national community survey of Australians. BMJ Open 2015;5:e007436. doi:10.1136/bmjopen-2014007436

- Prepublication history and additional material is available. To view please visit the journal (http://dx.doi.org/ 10.1136/bmjopen-2014007436)

Received 11 December 2014 Revised 20 March 2015 Accepted 25 March 2015

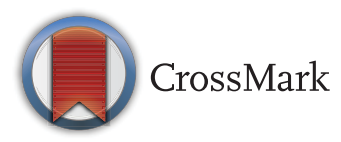

${ }^{1}$ Centre for Research in Evidence-Based Practice, Bond University, Robina, Australia

${ }^{2}$ School of Public Health, University of Sydney, Sydney, Australia

Correspondence to Raymond Moynihan; raymoynihan@bond.edu.au

\section{ABSTRACT}

Objective: Overdiagnosis occurs when someone is diagnosed with a disease that will not harm them. Against a backdrop of growing evidence and concern about the risk of overdiagnosis associated with certain screening activities, and recognition of the need to better inform the public about it, we aimed to ask what the Australian community understood overdiagnosis to mean.

Design, setting and participants: Content analysis of verbatim responses from a randomly sampled community telephone survey of 500 Australian adults, between January and February 2014. Data were analysed independently by two researchers.

Main outcome measures: Analysis of themes arising from community responses to open-ended questions about the meaning of overdiagnosis.

Results: The sample was broadly representative of the Australian population. Forty per cent of respondents thought overdiagnosis meant exaggerating a condition that was there, diagnosing something that was not there or too much diagnosis. Twenty-four per cent described overdiagnosis as overprescribing, overtesting or overtreatment. Only $3 \%$ considered overdiagnosis meant doctors gained financially. No respondents mentioned screening in conjunction with overdiagnosis, and over $10 \%$ of participants were unable to give an answer.

Conclusions: Around half the community surveyed had an approximate understanding of overdiagnosis, although no one identified it as a screening risk and a quarter equated it with overuse. Strategies to inform people about the risk of overdiagnosis associated with screening and diagnostic tests, in clinical and public health settings, could build on a nascent understanding of the nature of the problem.

\section{INTRODUCTION}

Overdiagnosis occurs when a person is diagnosed with a disease that would not have harmed them, and evidence is emerging that the problem is associated with a range of

\section{Strengths and limitations of this study}

- This is the first study to ask the general community about the meaning of overdiagnosis, a problem attracting growing research attention.

- Our survey sample was generally representative of the Australian community.

- Findings offer a unique and rich data set of public understanding, to help inform strategies to communicate better about overdiagnosis and overuse.

- Limitations arise from the modest response and cooperation rates, though similar rates are now common with telephone surveys.

- Another limitation arises because survey participants had little time to reflect on the meaning of overdiagnosis before responding.

conditions. ${ }^{1}$ There are a number of drivers of overdiagnosis, including the medicalisation of risk, ${ }^{2}$ improvements in diagnostic technology that identifies ever-smaller 'abnormalities', widening disease definitions and cultural enthusiasm for early detection. ${ }^{3}$ Appearing in the medical literature as early as the 1970s, the complex and counterintuitive concept is attracting increasing research attention as part of a wider interest in preventing avoidable medical excess, and is manifested in initiatives including JAMA Internal Medicine's Less is More ${ }^{4}$ Choosing Wisely $^{5}$ and The BMJ's Too Much Medicine series on expanding disease definitions and the risk of overdiagnosis. ${ }^{6}$ To our knowledge, however, there are no data on what the community understands overdiagnosis to mean.

Narrowly defined, overdiagnosis occurs when a healthy person is diagnosed with a disease or condition that will not go on to cause them harm, and can occur, for example, when screening programmes lead to the diagnosis of cancers that will never 
progress. ${ }^{1}$ More broadly, overdiagnosis is part of the wider problem of too much medicine, ${ }^{6}$ and there is currently scientific discussion about how to precisely delineate overdiagnosis from other issues including over-medicalisation and overutilisation. ${ }^{7}$

While debate about the nature and extent of overdiagnosis continues, ${ }^{8}$ there is a growing consensus that it is a source of significant harm for those who receive an unnecessary diagnosis, and a waste for the health system, with evidence most well advanced in the field of cancer screening. After assessing all available evidence, an independent panel in 2012 estimated 19\% of breast cancers detected during mammography screening may be overdiagnosed: defined as detection of cancers that do not progress to be symptomatic and "would never have been found were it not for the screening test". ${ }^{9}$ In the same year, the US Preventive Services Task Force pointed to "convincing evidence that PSA-based screening leads to substantial overdiagnosis of prostate tumours', with estimates ranging from $17 \%$ to $50 \% .^{10}$

This evidence has contributed to recognition of the need for greater professional and public awareness of the problem. In 2013, a working group, convened under the auspices of the US National Cancer Institute, stated, "Physicians, patients, and the general public must recognize that overdiagnosis is common and occurs more frequently with cancer screening". ${ }^{11}$ In late 2014, the science and technology committee of the UK parliament produced a report calling for routine communication of the benefits and risks of screening programmes. ${ }^{12}$ In November 2014, a report from the Academy of Medical Royal Colleges signalled a 'cultural shift' away from unnecessary medical care, ${ }^{13}$ underscoring the need for new clinical approaches, including 'de-prescribing' strategies designed to confront inappropriate polypharmacy. ${ }^{14}$ In order to inform ongoing scientific and policy debates about how to effectively communicate about overdiagnosis and related overuse, in clinical and public health settings, we aimed to discover what the community currently understood overdiagnosis to mean.

\section{METHODS}

We conducted a Computer-Assisted Telephone Interview (CATI) survey of randomly selected adult Australians to explore understanding of overdiagnosis. The survey recruited 500 Australians aged 18 years and older, using a randomly selected dual frame sample, including landlines and mobile phones. As per formulae from the American Association for Public Opinion Research (AAPOR),${ }^{15}$ we calculated the AAPOR response ratewhich includes in its denominator estimations of the proportion of cases of unknown eligibility that are actually eligible and calculations involve all households including those where no contact at all was made-and the AAPOR cooperation rate-which excludes un-contacted households, and calculates the proportion of those contacted who cooperated.
A survey questionnaire was developed iteratively and piloted with a convenience sample of 20 adult Australians and then through an experienced social research company, The Social Research Centre, with an additional 20 recruited participants. The survey was introduced with the words: "We're doing a short survey across Australia about community views on the way doctors diagnose diseases. This is an emerging issue and the results will help researchers find better ways for doctors to communicate about the risks and benefits of medical tests and treatments" (see online supplementary file 1).

Participants were assured responses would be anonymous and not recorded, and in order to maximise informed consent, a Participant Information Sheet was developed and made available to be read on request, and posted on accessible websites. The information sheet and the process for seeking informed consent were explicitly approved by BUHREC. The final CATI survey lasted for an average of $15 \mathrm{~min}$ and was conducted by The Social Research Centre between January and February 2014.

Following an initial question asking "Have you seen or heard the term 'overdiagnosis' before today?", participants who answered "yes" were then asked "What do you understand the term 'overdiagnosis' to mean?"; if they had answered "no" to the first question, or "don't know" to the second, they were asked, "What do you think the term 'overdiagnosis' means?" If needed, interviewers would add a clarifying statement: "We are discussing overdiagnosis of medical illnesses, diseases and conditions". Responses were transcribed verbatim. Quantitative elements of the survey are being analysed and reported separately from this qualitative analysis of participants' verbatim responses.

On completion of the survey, we used content analysis of the verbatim responses to identify and code emergent themes that captured the diverse understanding of overdiagnosis. ${ }^{16}$ Two authors (RM, BN) independently reviewed the verbatim responses from the 500 participants, and identified salient themes. To ensure rigour of the analysis, we used constant comparison methods ${ }^{17} 18$ to look for similarities and differences in the themes across responses. The two sets of independently identified major themes were documented and discussed with coauthors (JD, JH, KM, AB), and an initial coding framework of themes was developed and then pilot tested, by independent double coding of 50 of the verbatim responses by $\mathrm{RM}$ and $\mathrm{BN}$. By comparing and reviewing the pilot data, and with more discussion with the experienced qualitative researcher on our research team (KM), the final coding framework was then developed. For final coding, the 500 verbatim responses were randomised, and two authors (RM, BN) independently coded 300 responses each, including 100 responses that were double coded, resulting in agreement in over $80 \%$ of cases in assigning responses to themes. A single response could be coded to more than one theme. 


\section{RESULTS}

Of 4156 landline and mobile calls initiated, 3307 eligible numbers were identified and contact made with 1282 numbers, from which 500 completed interviews, plus 20 pilots, were achieved (figure 1). The response rate was 20.4\% (AAPOR, RR3) and the cooperation rate (people who completed the survey, as a proportion of those who completed, plus those who refused), $43.8 \%$ (AAPOR, COOP3). The sample was generally representative, but included a higher proportion of women and older adults than the general Australian community, as is typical with telephone-based health surveys, and slightly higher levels of education (table 1).

Of 500 participants, 433 offered a response to the question about the meaning of the term overdiagnosis. The average response was 14 words. After independent content analysis of themes by $\mathrm{RM}$ and $\mathrm{BN}$, for nine major themes there was clear agreement between the two authors on the nature of the theme. Following discussion with coauthors and piloting of the coding framework, a final list of 10 themes was agreed on. Following independent double coding of 100 responses, in 82 cases there was agreement on the theme/s a response was coded to, including 5 cases where one or another coder assigned the response to an additional theme as well. All discrepancies were resolved by discussion.
The final 10 themes and their accompanying explanations are listed in table 2. These 10 themes were then divided into three categories described as: (1) approximate understanding of overdiagnosis; (2) overuse; and (3) other. The most prevalent theme of the responses was 'exaggerating something that is there', which included responses suggesting overdiagnosis meant 'diagnosing a condition to be more serious/severe than what it actually is; overmedicalising; overcomplicating'. Twenty-two per cent of responses were coded as fitting into this theme, exemplified by the comment, "Someone's condition has been made out to be worse than what it is" (table 3). Responses in this theme revolved around ideas that diagnostic labels made problems seem more severe than what they were, causing unnecessary fear or worry (see more examples of all themes in box 1). Another example of a comment in this theme was: "When a patient presents with symptoms and the doctor diagnoses it as something more serious than it is, for example, when a boisterous child is diagnosed with ADHD when they just have a lot of energy". ADHD was the condition most commonly mentioned, appearing in a total of 14 responses (including ADD and hyperactivity). Other conditions mentioned as examples of overdiagnosis included cancer (3 times), with one mention only for asthma, autism, cholesterol and mental illness.

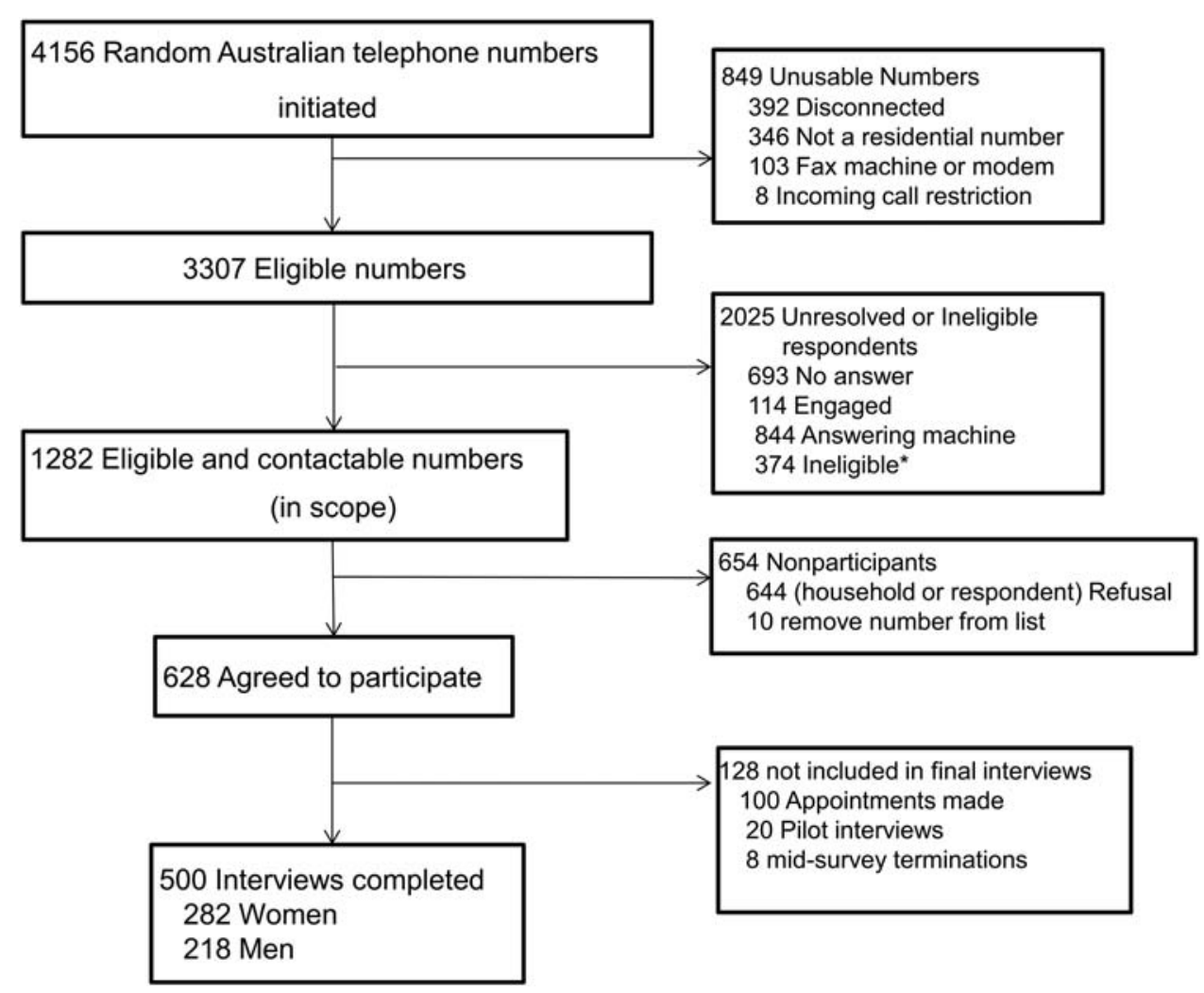

Figure 1 Participant Recruitment for Telephone Interview Survey of 500 Australians. Ineligible participants included: persons under 18 years of age; those with a medical condition rendering them physically unable to complete the interview; people with language difficulties; respondents away for duration of fieldwork; people claiming to have carried out survey or named person not known. 
Table 1 Characteristics of respondents questioned about the meaning of overdiagnosis

\begin{tabular}{|c|c|}
\hline Characteristic & $\begin{array}{l}\text { Number of survey } \\
\text { respondents } n=500(\%)\end{array}$ \\
\hline \multicolumn{2}{|l|}{ Age, years } \\
\hline $18-49$ & $215(43.0) *(57.8)$ \\
\hline $50-$ & $285(57.0) *(42.2)$ \\
\hline \multicolumn{2}{|l|}{ Sex } \\
\hline Men & $218(43.6) *(49.4)$ \\
\hline Women & $282(56.4) *(50.6)$ \\
\hline \multicolumn{2}{|l|}{ Education } \\
\hline$<$ High school & $74(14.8) *(26.9)$ \\
\hline High school graduate & $169(33.8) *(38.7)$ \\
\hline $\begin{array}{l}\text { Bachelor degree/advanced } \\
\text { diploma }\end{array}$ & $168(33.6) *(26.5)$ \\
\hline >Bachelor degree & $89(17.8) *(7.7)$ \\
\hline \multicolumn{2}{|l|}{ Employment } \\
\hline Employed & $298(59.6)$ \\
\hline Unemployed & $20(4)$ \\
\hline Not working & $182(36.4)$ \\
\hline \multicolumn{2}{|l|}{ Cancer diagnosis } \\
\hline Yes & $70(14.0)$ \\
\hline No & $430(86.0)$ \\
\hline
\end{tabular}

Related to the 'exaggeration' theme was the theme described as 'diagnosing something not there', which included responses that defined overdiagnosis as 'diagnosing a condition that the person does not actually have/does not exist' and exemplified by the comment "Sort of pre-empting a potential disease when there isn't one". This theme occurred in $10 \%$ of responses. Also related was the theme "too much or too many diagnoses', explained as 'doctors making a diagnosis more frequently than what is needed/people being diagnosed with too many conditions'. This theme was exemplified by the response, "For example cholesterol, they just use a level in the blood and if you are over the level you have that and they lower the level so everyone has it", and this occurred in $9 \%$ of responses. While none of the three related themes corresponds exactly with the current definitions of overdiagnosis being debated within the scientific community, they can be seen to approximate an understanding of the problem of an unnecessary and unhelpful diagnosis.

The second most common set of themes related to overuse of interventions, occurring in $24 \%$ of responses. The theme of 'overprescribing'-which was described as 'prescribing too many medications/more than is needed'-ran through $14 \%$ of responses, exemplified by the comment, "A doctor is handing out medication willy nilly." This theme related closely to 'overtreatment'defined as "unnecessary medical interventions and services provided, including referrals; overservicing.' The overtreatment theme was exemplified by the comment, "Overservicing or providing greater service than is essential for the correct diagnosis" and occurred in 5\% of responses. The theme 'overtesting'-defined as 'a doctor performing or a person having too many unnecessary tests to get a diagnosis' - was exemplified by the comment "Where too many tests are done, particularly with prostate cancer", and occurred in $7 \%$ of responses.

Relatively small numbers of participants made responses coded into themes including 'doctors looking too much', (4\%) 'patients driving it', (4\%) 'wrong diagnosis', (4\%) and 'doctors' financial gain' (3\%). Around $13 \%$ of

Table 2 Coding framework for analysis of responses to "What do you think overdiagnosis means?"

\begin{tabular}{ll}
\hline Theme & Explanation of theme \\
\hline $\begin{array}{l}\text { Overdiagnosis } \\
\text { Exaggerating something that is there }\end{array}$ & $\begin{array}{l}\text { Diagnosing a condition to be more serious/severe than what it actually is; } \\
\text { overmedicalising; overcomplicating } \\
\text { Diagnosing something that is not there } \\
\text { Too much diagnosis/too many diagnoses } \\
\text { Doctors making a diagnosis more frequently than what is needed/people } \\
\text { being diagnosed with too many conditions }\end{array}$ \\
$\begin{array}{l}\text { Overprescribing } \\
\text { Overtreatment }\end{array}$ & $\begin{array}{l}\text { Prescribing too many medications-more than is needed } \\
\text { Unnecessary medical interventions and services provided, including referrals; } \\
\text { overservicing } \\
\text { A doctor performing or a person having too many unnecessary tests to get a } \\
\text { diagnosis }\end{array}$ \\
$\begin{array}{l}\text { Others } \\
\text { Doctors looking too much into things }\end{array}$ & $\begin{array}{l}\text { Doctors looking too hard, too much or too often, for a problem to diagnose } \\
\text { Patients/people who search for too much unnecessary medical information or } \\
\text { are unusually anxious or worried about their health } \\
\text { Wrongly diagnosed with a condition (with no suggestion of exaggerating } \\
\text { something) } \\
\text { doctors whose ultimate goal is to make money or cover themselves for }\end{array}$ \\
financial or litigation reasons
\end{tabular}


Table 3 What do you think overdiagnosis means? Response theme, example and frequency

\begin{tabular}{|c|c|c|c|}
\hline Theme & Example of comment & Number & $\begin{array}{l}(\% \text { of } \\
500)^{*}\end{array}$ \\
\hline \multicolumn{4}{|l|}{ Overdiagnosis } \\
\hline $\begin{array}{l}\text { Exaggerating something } \\
\text { that's there }\end{array}$ & "Someone's condition has been made out to be worse than what it is" & 112 & 22 \\
\hline $\begin{array}{l}\text { Diagnosing something that's } \\
\text { not there }\end{array}$ & "Sort of pre-empting a potential disease when there isn't one" & 48 & 10 \\
\hline $\begin{array}{l}\text { Too much/too many } \\
\text { diagnoses }\end{array}$ & $\begin{array}{l}\text { "I take it to mean something like ADHD, where previously it hadn't } \\
\text { been diagnosed and now it is and suddenly people find it everywhere" }\end{array}$ & 45 & 9 \\
\hline \multicolumn{4}{|c|}{ ( } \\
\hline Overprescribing & "A doctor is handing out medication willy nilly" & 69 & 14 \\
\hline Overtreatment & $\begin{array}{l}\text { "Overservicing or providing greater service than is essential for the } \\
\text { correct diagnosis" }\end{array}$ & 26 & 5 \\
\hline Overtesting & "Where too many tests are done, particularly with prostate cancer" & 33 & 7 \\
\hline \multicolumn{4}{|c|}{ 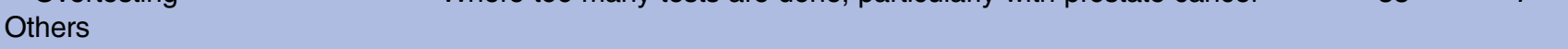 } \\
\hline Doctors looking too much & "Looking too far into a problem" & 21 & 4 \\
\hline Patients driving it & $\begin{array}{l}\text { "People get on the internet and diagnosing themselves with things } \\
\text { they don't have" }\end{array}$ & 22 & 4 \\
\hline Wrong diagnosis & $\begin{array}{l}\text { "That they haven't diagnosed you correctly or they have given you the } \\
\text { wrong diagnosis" }\end{array}$ & 20 & 4 \\
\hline Doctors' financial gain & $\begin{array}{l}\text { "They want to make more cost for patients and make more money or } \\
\text { they sometimes go further to cover themselves" }\end{array}$ & 17 & 3 \\
\hline \multicolumn{4}{|l|}{ Non-responses } \\
\hline Did not respond at all & & 67 & 13 \\
\hline $\begin{array}{l}\text { Miscellaneous/do not know/ } \\
\text { unsure }\end{array}$ & & 61 & 12 \\
\hline
\end{tabular}

participants failed to respond, and for another $12 \%$, responses were unable to be categorised into the final 10 themes, because, for example, a participant answered by saying 'probably overdiagnosis'. No responses mentioned screening.

\section{DISCUSSION}

Our survey of 500 Australian adults found almost half of participants thought the term overdiagnosis meant exaggerating a problem that exists, diagnosing something that is not there, or deploying too many diagnoses and another quarter equated the term with some form of overuse, including overprescribing, overtesting or overtreating. A significant minority offered either no response, or a response unable to be categorised. Only a tiny proportion gave responses that made mention of doctors' financial gain, and, notably, no respondent mentioned the association between overdiagnosis and screening.

This study has several limitations. First, the brevity of participant responses made coding into themes more difficult for answers where comprehensibility was in doubt, and roughly 1 in 10 responses were unable to be categorised into our final 10 themes. Second, the openended question to participants about the meaning of overdiagnosis was asked at the very start of the survey, enabling valuable analysis of unprompted understanding of the term, but not giving participants much time to reflect or think through responses. A third limitation arises from the AAPOR response rate of $20.4 \%$ and cooperation rate of $43.8 \%$. While modest, these rates are now, however, common and satisfactory for community surveys of this type. In 2012, the well regarded Pew Research Centre stated its standard telephone surveys were achieving AAPOR response rates of $9 \%$ and cooperation rates of $14 \%$, and that the $9 \%$ response rate was similar to that achieved by other major survey organisations. ${ }^{19}$ With the rates achieved in our survey, there is a possibility of systematically different responses between respondents and non-respondents, though this possibility is lessened by the general representativeness of sample respondents.

Study strengths include the strong level of agreement on themes in the initial independent coding of the 500 responses, pointing to a thematic coherence in the community's response, and notwithstanding demographic variations between our random sample and population data, the study's 500 Australian adults were generally representative. Most importantly, to the best of our knowledge this is the first time internationally that general community members have been asked what they understand overdiagnosis to mean, with responses providing a unique data set. Other data on public understanding or views about overdiagnosis are extremely limited. A quantitative survey by Schwartz et $a l^{20}$ in 2004 found widespread enthusiasm for screening, unmodified by awareness of potential harms, while a qualitative study 
Box 1 What do you think overdiagnosis means? Additional examples of responses

\section{Exaggerating something that is there}

"I'm guessing it means a mountain made out of a mole hill" "Making diseases more severe than they are"

"When a patient presents with symptoms and the doctor diagnoses it as something more serious than it is, for example, when a boisterous child is diagnosed with ADHD when they just have a lot of energy"

"Someone's condition has been made out to be worse than what it is" "Maybe reading too much into symptoms"

"Something that's not really serious making it sound as though it is really bad"

"They over diagnose what's going on with a person and they scare them more than they need to"

"It might mean that they've given a diagnosis that you're far worse off than you really are"

"When you're diagnosed with something but it's not as life threatening as it's being explained to be"

Diagnosing something that is not there

"When they assign diseases to people who aren't ill"

"Diagnosing a disease someone doesn't have"

"Doctor seeing things that aren't there"

"There is so many different ailments around and now there are so many different medications now it's possible that doctors are describing things that aren't there"

Too much diagnosis/too many diagnoses

"When there are more people given a label than you would expect to be the case"

"For example cholesterol, they just use a level in the blood and if you are over the level you have that and they lower the level so everyone has it"

"I take it to mean something like ADHD, where previously it hadn't been diagnosed and now it is and suddenly people find it everywhere"

Overprescribing

"Too much medication"

"Doctors trying to give out drugs that don't need to be taken to cure an ailment"

"You are being given too much medication when you don't need it" Overtreatment

"If you have an illness where there are too many treatments for it" "Overservicing of a patient's needs"

Overtesting

"Doctors sending people for too many tests"

"I think they send you off to have this test or that test and it's all a bit unnecessary"

Doctors looking too much

"When a doctor is looking for too many things"

Patients driving it

"If you go on the internet and you're looking at things you're just taking the information but it's probably the wrong information"

Wrong diagnosis

"The doctor wrongly diagnoses"

Doctors' gain

"Generally speaking it's a doctor who is milking the system to get more funds"

published in 2013, involving focus groups with 50 Australian women aged 40-79, found few had heard of overdiagnosis, though there was a desire to know more. ${ }^{21}$ In 2014, researchers found that brief written information about overdiagnosis and mammography, of the sort currently sent to women in the UK, was incompletely understood and may not be enough to facilitate informed choice. $^{22}$

At a time when the scientific community is still debating the definition of overdiagnosis, it makes little sense to judge the accuracy of community comprehension. Instead, we interpret the results to suggest that while many people grasp the basic idea, 'overdiagnosis means too many unnecessary diagnoses', many others failed to offer even an approximate understanding. For clinicians attempting to explain to their patients the counter-intuitive concepts such as the risk of overdiagnosis or the value of choosing not to test or to reduce or stop medication, for instance, ${ }^{13}{ }^{14}$ our results point to an encouraging though limited reservoir of community recognition of the potential dangers of excess. Clinicians may also take heart from how very few respondents identified doctors' financial gain as relevant to the meaning of overdiagnosis. Our finding that almost one in four respondents associated overdiagnosis with overuse suggests overdiagnosis might be best communicated about not in isolation, but within a wider context of its potential harms, including overuse. And finally, we believe the failure to associate overdiagnosis with screening should be interpreted as a strong signal to policymakers to introduce more routine communication about potential benefits and harms into screening programmes.

While there are ongoing and complex debates about how to define and measure overdiagnosis, ${ }^{7}$ and resulting disagreements over its magnitude and extent, ${ }^{8}$ there is a growing consensus around the need to better communicate with the community about the problem, particularly as a risk of screening. Our findings offer a rich data set of lay understanding to researchers and policymakers, to help inform development of effective communication strategies. Notwithstanding the complexity of the issues, the community responses provide some refreshingly simple and clear insights, reinforcing the need to intimately involve community members in developing and evaluating future communication strategies.

Twitter Follow Jolyn Hersch at @ herscheybar

Acknowledgements The authors would like to thank Chrissy Erueti at the Centre for Research in Evidence-Based Practice, (CREBP) Faculty of Health Sciences and Medicine, Bond University, for on-going support and assistance members of the Bond University Human Research Ethics Committee for their input into survey; and staff at the Social Research Centre, including Shane Compton, who were involved in developing and running the survey. The authors are deeply grateful to all survey participants for volunteering their time for this research.

Contributors RM, KM and JD obtained study funding. RM, BN, JH, EB, JD, $A B$ and $K M$ designed the survey. RM and $B N$ analysed the responses to the survey question about the meaning of overdiagnosis. KM supervised all aspects of this study. RM, BN, EB and KM analysed the data arising from the content analysis. RM developed the first draft of the manuscript, and all authors critically reviewed it and contributed to revisions before submission. $\mathrm{RM}$ is the guarantor. 
Funding RM's and JD's positions receive funding from a Screening and Test Evaluation Program (STEP) grant from the National Health and Medical Research Council (http://www.nhmrc.gov.au) (NHMRC) \#633003; EB's position receives funding from an Australia Fellowship grant: Glasziou NHMRC \#527500; the survey received part funding from a Bond University Vice-Chancellors Research Grant (http://www.bond.edu.au) and part funding from a NHRMC (STEP) grant \#633003.

Competing interests $\mathrm{RM}, \mathrm{JD}$ and $\mathrm{AB}$ are members of the steering committee that helped organise the 2013 and 2014 Preventing Overdiagnosis conferences.

Ethics approval Bond University Human Research Ethics Committee.

Provenance and peer review Not commissioned; externally peer reviewed.

Data sharing statement Survey participant responses analysed in this paper will be available, via the repository used by Bond University, on publication.

Open Access This is an Open Access article distributed in accordance with the Creative Commons Attribution Non Commercial (CC BY-NC 4.0) license, which permits others to distribute, remix, adapt, build upon this work noncommercially, and license their derivative works on different terms, provided the original work is properly cited and the use is non-commercial. See: http:// creativecommons.org/licenses/by-nc/4.0/

\section{REFERENCES}

1. Welch HG, Schwartz LM, Woloshin S. Overdiagnosed: making people sick in the pursuit of health. Boston: Beacon Press, 2011.

2. Armstrong D. The rise of surveillance medicine. Sociol Health IIIn 1995;17:393-404.

3. Moynihan R, Doust J, Henry D. Preventing overdiagnosis: how to stop harming the healthy. BMJ 2012;344:e3502.

4. Grady D, Redberg R. Less is more: how less health care can result in better health. Arch Intern Med 2010;170:749-50.

5. Choosing Wisely. US physician groups identify commonly used tests or procedures they say are often not necessary. Press release, 2012. http:// choosingwisely.org/wp-content/uploads/2012/03/033012_ChoosingWisely-National-Press-RIs-FINAL.pdf (accessed 9 Dec 2014).

6. Glasziou P, Moynihan R, Richards T, et al. Too much medicine; too little care. BMJ 2013;346:44247.

7. Carter SM, Rogers W, Heath I, et al. The challenge of overdiagnosis begins with its definition. BMJ 2015;350:h869.
8. Carter JL, Coletti RJ, Harris RP. Quantifying and monitoring overdiagnosis in cancer screening: a systematic review of methods. BMJ 2015;350:g7773.

9. Independent UK Panel on Breast Cancer Screening. The benefits and harms of breast cancer screening: an independent review. Lancet 2012;380:1778-86.

10. Moyer VA on behalf of the US Preventive Services Task Force. Screening for prostate cancer: US preventive services task force recommendation statement. Ann Intern Med 2012;157:120-34.

11. Esserman L, Thompson I, Reid B. Overdiagnosis and overtreatment in cancer an opportunity for improvement. JAMA 2013;310:797-8.

12. House of Commons Science and Technology Committee. National Health Screening. Third Report of Session 2014-15; 29 October 2014. http://www.publications.parliament.uk/pa/cm201415/cmselect/ cmsctech/244/244.pdf (accessed 9 Dec 2014).

13. Academy of Royal Medical Colleges. Protecting resources, promoting value: a doctor's guide to cutting waste in clinical care. November 2014. http://www.aomrc.org.uk/dmdocuments/Promoting \%20value\%20FINAL.pdf (accessed 9 Dec 2014).

14. Scott I, Anderson K, Freeman C, et al. First do no harm: a real need to deprescribe in older patients. Med J Aust 2014;201:1-3.

15. The American Association for Public Opinion Research. Standard definitions: final dispositions of case codes and outcome rates for surveys. 7th edn. AAPOR, 2011. http://www.aapor.org/ AAPORKentico/AAPOR Main/media/MainSiteFiles/ StandardDefinitions2011_1.pdf (accessed 21 Mar 2015).

16. Fereday J, Muir-Cochrane E. Demonstrating rigor using thematic analysis: a hybrid approach of inductive and deductive coding and theme development. Int J Qual Methods 2006;5:1-11.

17. Hewitt-Taylor J. Use of constant comparative analysis in qualitative research. Nurs Stand 2001;15:39-42.

18. Pope C, Ziebland S, Mays N. Qualitative research in health care. Analysing qualitative data. BMJ 2000;320:114

19. The Pew Research Centre, Assessing the Representativeness of Public Opinion Surveys May 15 2012. http://www.people-press.org/ 2012/05/15/assessing-the-representativeness-of-public-opinionsurveys/ (accessed 9 Dec 2014)

20. Schwartz LM, Woloshin S, Fowler FJ, et al. Enthusiasm for cancer screening in the United States. JAMA 2004;291:71-8.

21. Hersch J, Jansen J, Barratt A, et al. Women's views on overdiagnosis in breast cancer screening: a qualitative study. BMJ 2013;346:f158.

22. Waller J, Whitaker KL, Winstanley $\mathrm{K}$, et al. A survey study of women's responses to information about overdiagnosis in breast cancer screening in Britain. Br J Cancer 2014;111:1831-5. 